\title{
Las relaciones entre Felipe IV y Carlos II de Inglaterra, durante el protectorado de Cromwell (1656-1659)
}

\author{
Josefina Castilla Soto *
}

Con el estallido de la revolución inglesa capitaneada por Cromwell y el consiguiente ajusticiamiento del monarca inglés, Carlos I, se inició el destierro de su hijo y sucesor, Carlos II, en diferentes países del continente europeo, el cual, lejos de resignarse, buscó con la ayuda de sus consejeros, alianzas y respaldos traducidos en hombres y dinero, como medio de intentar la recuperación del trono, alentado por la existencia segura de un partido realista que le aguardaba en Inglaterra.

El exilio de Carlos II se vio profundamente mediatizado por los hilos de la diplomacia internacional en cuyo entramado concurrían de forma preeminente, la Francia de Mazarino, la nueva potencia inglesa encabezada por Cromwell en busca de un espacio importante en el concierto europeo y la Monarquía hispánica cuya delicada situación política y económica a nadie se ocultaba.

Precisamente, Felipe IV, se convirtió en el anfitrión de Carlos II en los años inmediatamente anteriores a la Restauración de la Monarquía inglesa, ocurrida en 1660.

* Profesora de Historia Moderna de la UNED. 
La revolución inglesa estalló como consecuencia de la pugna existente entre dos tendencias protestantes diferentes. Por un lado, estaba la iglesia anglicana cuya cabeza visible era el monarca y que atraía, principalmente, a la clase nobiliaria y por otro, las creencias puritanas de corte calvinista que se daban, sobre todo, entre la burguesía.

Mientras los anglicanos defendían a ultranza la monarquía absoluta, los puritanos, siguiendo fielmente los principios calvinistas, eran partidarios de despedir al monarca, mediante una insurrección, si éste se conducía tiránicamente.

Así pues, resultaba evidente para estos burgueses calvinistas que el Rey de Inglaterra, dada su tendencia absolutista, se estaba comportando de una manera despótica.

En 1640, al igual que en la península ibérica, estalló el conflicto inglés cuando el Parlamento exigió al monarca, entonces Carlos I, el reconocimiento de la supremacía de la institución parlamentaria frente a las decisiones reales.

La revolución propiamente dicha se inició cuando el Parlamento condenó al ministro Strafford ${ }^{1}$ y después al arzobispo Laud, representante de ia Iglesia oficial.

Carlos I se vio obligado a abandonar Londres y organizó un ejército, desencadenándose una auténtica guerra civil ${ }^{2}$.

En 1647 el ejército parlamentario, al frente del cual estaba Oliver Cromwell, derrotó a las fuerzas reales e hizo prisionero al monarca. La idea de los puritanos era clara: derrocar la monarquía, proclamar la república y acabar con los privilegios de la aristocracia. El triunfo fue total. El 30 de enero de 1649, Carlos I era ejecutado, el Parlamento quedaba disuelto y se proclamaba la república mientras que la nobleza quedaba

1 C. V. WEDGWOOD, Strafford, Londres 1936; H. F. KEARNEY, Strafford in Ireland, 16331641. Londres 1959.

2 J. Evan, Charles I, Londres 1933; D. OGG, England under the reing of Charles I, Oxford 1955, 2 vols.; D. MATHEW, The Age of Charles I. Londres 1951; C. V. WedGWOOd, The King's Peace, 1637-1641. Londres 1955; Id., The King's War, 1641-1647. Londres 1958; H. R. WILLIAMSON, Charies and Cromwell. Londres 1946. 
relegada a un segundo plano ${ }^{3}$. Todo el poder quedaba concentrado en la persona de Cromwell.

Paradójicamente se había pasado de un absolutismo a otro. Según Saavedra Fajardo, en los movimientos de revuelta, cuando el pueblo «pretende violentamente su libertad», suele encontrar, al encomendarse irreflexivamente a un poderoso que lo capitanee, la dura servidumbre de una tiranía ${ }^{4}$. Esto, precisamente, ocurrió en Inglaterra.

Carlos, Príncipe de Gales, entretanto, se instaló en La Haya donde los Estados Generales le trataron con respeto aunque, en medio de ciertas reservas.

Posteriormente, y a pesar de la oposición de sus más hábiles consejeros, se instaló en Saint-Germain, con la excusa de visitar a su madre. La presencia del Príncipe en Francia comprometía seriamente la política amistosa que Mazarino trataba de desplegar respecto a la república inglesa ${ }^{5}$, por lo que decidió trasladarse a Jersey, estado del que aún se consideraba en posesión.

De allí pasó a Escocia donde un grupo de monárquicos, preparaba una rebelión mientras el Príncipe de Gales era proclamado rey con el nombre de Carlos II, tras haber firmado el Covenant.

Sin duda, la guerra de Escocia es la guerra del miedo contra el regreso de la Monarquía y sus venganzas ${ }^{6}$. Carlos II se dispuso a jugar la última baza frente al éxito de la revolución, sin embargo, las sucesivas

3 M. AshleY, Oliver Cromwell and the Puritan Revolution. Londres 1958; J. BuCHAN, Oliver Cromwell. Londres 1934; S. R. GARDINER, The constitutional documents of the Puritan Revolution. Oxford 1936; C. H. FIRTH, Cromwell's Army. Londres 1962; M. GuIzot, Histoire de la Republique d'Anglaterre et de Cromwell. París 1964, 2 vols; R. AsHron, The english civil war: conservatims and revolution 1603-1649. Londres 1978; D. HIRST, Authority and conflict: England 1603-1658. Londres 1986. p. 442 .

4 Citado por J. A. Maravall, Estado moderno y mentalidad social. Madrid 1972, vol. I,

5 «Los príncipes extranjeros empiezan a mirar al rey como un hombre tan indolente y tan poco cuidadoso de sus propios asuntos, que no creen prudente malquistarse por socorrerlo, con enemigos tan poderosos como lo serán probablemente sus rebeldes vasallos" (citado por M. Guizot, Historia de la república de Inglaterra y de Cromwell. Madrid 1858, p. 68).

${ }^{6}$ E. Momiglano, Cromwell, Lord Protector de Inglaterra. Barcelona 1941, p. 87. 
derrotas en Durbar y Worcester, brindaron el triunfo a Cromwell por lo que el rey inglés regresó nuevamente a Francia.

La Monarquía hispánica se apresuró, entonces, por medio de su embajador don Alonso de Cárdenas, a reconocer a la nueva República de Inglaterra lo que propició el envío, por parte de Cromwell, de un representante diplomático, don Antonio Ascham, quien caía asesinado en Madrid, junto con su secretario, por un grupo de ingleses realistas. Aunque el gobierno se esforzó por probar su inocencia en tan lamentable suceso, las relaciones se hicieron cada vez más tensas.

Además, Cromwell, a cambio de su acercamiento a la Corona hispana, demandaba tolerancia religiosa para los ingleses residentes en España y admisión de los comerciantes británicos en el comercio colonial español. Concretamente, respecto al primer punto, la Inquisición se negó a propiciar la tolerancia y éste fue uno de los motivos que inclinaron al Protector hacia el bando francés?.

Por otra parte, Cromwell eligió a Francia para el establecimiento de una alianza porque era consciente de que como enemigo de la Monarquía hispana tenía más que ganar y menos que perder que como enemigo de Francia. Al parecer, el rey galo, había ofrecido al Protector, millón y medio de florines, además de fuerzas para facilitarle el desembarco en Flandes, donde Cromwell podría obtener un suculento botín ${ }^{8}$.

En 1655 estallaron las hostilidades entre España e Inglaterra ensombreciendo gravemente el panorama en los Países Bajos donde aliados franceses e ingleses se disponían a actuar de forma conjunta en vísperas de producirse el relevo en el gobierno de Flandes entre el archiduque Leopoldo y don Juan de Austria, hijo bastardo de Felipe IV.

También los territorios ultramarinos se resintieron de los ataques ingleses, los cuales adernás, lograron interceptar las flotas cargadas de plata en 1656 y 1657, perjudicando, aún más, la delicada situación de la economía hispana ${ }^{9}$.

R. García-Villoslada, Historia de la lglesia en España. Madrid 1979, vol. IV, p. 118. AGS, Estado, Leg. 2087.

9 A. Domínguez Ortiz, Política y Hacienda de Felipe IV, Madrid 1960. Mientras la economía hispana iba de bancarrota en bancarrota y se sumía cada vez más en una crisis con apariencias de irreversibilidad, en Inglaterra se producia el inicio del despegue comercial. En este sentido, ver C. HILL, De la reforma a la revolución industrial 1530-1780. Barcelona 1980. 
Las relaciones entre Felipe IV y Carlos /I de Inglaterra, durante el...

Carlos II, dado el acercamiento entre Francia y el Protector, se trasladó a Brujas, solicitando asilo y ayuda de España como medio de impulsar la colaboración de sus parciales, tanto de los residentes en Inglaterra como de los dispersos por el continente.

Tras los primeros titubeos y vacilaciones, el gobierno de Madrid se avino a firmar un tratado con el monarca inglés, el 12 de abril de $1656{ }^{10}$.

En realidad, se trataba de una liga ofensiva-defensiva que ratificaba la establecida en un acuerdo de paz, firmado en Madrid, el 15 de noviembre de 1630 , entre Felipe IV y el entonces Rey de Inglaterra, Carlos I ${ }^{11}$.

El Rey de España se comprometía a asistir al monarca inglés con 4.000 infantes y 2.000 caballos, a lo largo de 1656, siempre y cuando Carlos II, garantizara la lealtad de sus súbditos en algún puerto británico para hacer factible el desembarco de dichos efectivos.

Por su parte, el Rey inglés, una vez coronado en su país, ayudaría a Felipe IV en la recuperación de Portugal mediante levas de ingleses e irlandeses, así como de doce navíos de guerra, cuyo uso quedaría a disposición de la Monarquía hispana por un período de cinco años y perfectamente equipados con marineros, guarnición de soldados (cien cada uno), viveres, armas y municiones. Incluso, los ingleses devolverían a Felipe IV, las ocupaciones llevadas a cabo en las colonias americanas desde 1630 .

Así pues, quedaba establecido un acuerdo extraordinariamente ventajoso para el soberano inglés puesto que con él, tenía bastante que ganar (la ayuda hispana a su causa con posibilidades de arrastrar igualmente a otros países, amigos del Monarca católico) y nada que perder,

10 Las claúsulas de este tratado, en AHN, Estado, Leg. 2778, fol. 12; AGS, Estado, Leg. 2087 y AGS, Estado, Leg. 2088. Este acuerdo se firmó en Bruselas actuando como plenipotenciarios, por parte hispana, el archiduque Leopoldo, Gobernador y Capitán General de Flandes, el conde de Fuensaldaña, Gobernador General de las Armas y don Alonso de Cárdenas, del Consejo de Guerra y Embajador en Inglaterra. Por parte inglesa, los suscriptores fueron el marqués de Ormond y el conde de Rochester, del Consejo de Estado.

${ }^{11}$ En realidad, Carlos, Príncipe de Gales, había visitado Madrid en 1623 para pedir la mano de la infanta María, resultando un fracaso dicho viaje; de hecho, poco después estallaba la guerra hispano-inglesa. Ver R. RodRiguez-Monino SORIANo, Razón de estado y dogmatismo religioso en la España del siglo XVII. Negociaciones hispano-inglesas de 1623. Barcelona 1976. En 1630 llegaría la paz y con ella, el acuerdo entre España e Inglaterra. 
ya que todo quedaba supeditado a la futura Restauración de la Monarquía en Inglaterra.

Carlos II, instalado en Brujas, recabó el concurso en Flandes, de los irlandeses que se encontraban sirviendo en el ejército francés y solicitó asilo para su hermano, el duque de York ${ }^{12}$.

Esta iniciativa encontró el beneplácito de Madrid ya que en noviembre de 1656, llegaba a Flandes el hermano del monarca inglés, al que la generosidad de don Juan de Austria, entonces gobernador de los Países Bajos, proporcionó una jugosa pensión de mil quinientos escudos mensuales lo que propició las reprimendas del Consejo de Madrid, hacia el bastardo ${ }^{13}$.

Lo cierto es que la preocupación de la Corte estaba más que justificada y así fue participada a los mandos hispanos: El Consejo «no puede dejar de reparar en los inconvenientes que va produciendo la asistencia del Rey en Brujas, pues con la llegada de su hermano y con lo que el señor don Juan le aumentó las asistencias y con el sueldo del marqués de Ormond, ya son cinco mil escudos al mes» ${ }^{14}$.

Pronto, el monarca inglés, comenzó a solicitar el cumplimiento del tratado, a través del conde de Bristol. Sin embargo, don Juan de Austria, que además no había tenido ni arte ni parte en la suscripción de este acuerdo, no estaba dispuesto a restar del ejército de Flandes, los 4.000 soldados y los 2.000 caballos prometidos, encontrándose en tan precaria situación y en medio de una amenaza bélica continua ${ }^{15}$.

Don Alonso de Cárdenas excusó, ante el conde de Bristol, el cumplimiento del acuerdo pretextando la falta de puertos seguros en Inglate-

12 AGS, Estado, Leg. 2088. Así se refleja en una carta de don Alonso de Cárdenas al Rey, desde Bruselas, el 22 de mayo de 1656.

${ }_{13}$ «... que al señor don Juan se le diga, escuse entrar en semejantes cosas sin participarlas primero a V. Magestad...» (AGS, Estado, Leg. 2088. Consulta del Consejo de Estado, de 14 de diciembre de 1656).

${ }_{14}$ AGS, Estado, Leg. 2088. Reunión del Consejo de 16 de diciembre de 1656.

15 Ibidem. Carta de don Juan a Madrid, el 8 de octubre de 1656. Además, Flandes vivía en estos momentos el grave problema de la deserción de los soldados debido a la falta de pan, de munición y al retraso de las pagas, ver G. PARKER, El Ejército de Flandes y el Camino español (1567-1659). Madrid 1986, p. 267. 
Las relaciones entre Felipe IV y Carlos I/ de Inglaterra, durante el...

rra para efectuar el desembarco, condición ineludible para poner en marcha el tratado suscrito.

En 1657 la situación en Flandes se agravó aún más, en parte, debido al estrechamiento de relaciones franco-británicas cuya alianza, firmada en noviembre de 1655 se renovó, precisamente, el 23 de marzo de 1657. Así pues, don Juan, prosiguió las negociaciones con el rey inglés según el acuerdo suscrito por ambas partes. Se trataba, fundamentalmente, de ganar un aliado que en un futuro no muy lejano, podía estar al frente de Inglaterra.

Por otra parte, fortalecer a Carlos II hasta el punto de enfrentarlo con Cromwell, podía representar grandes ventajas para nuestros intereses ya que era un medio de desviar la actividad del Protector, hacia otros cometidos diferentes del ataque a las posesiones hispanas, tanto en Europa como en América.

El rey de Inglaterra, a través del conde de Bristol, elevó un memorial a don Luis de Haro en el que reflejaba su optimismo y la esperanza en la Restauración del trono inglés confiado, como estaba, en que Inglaterra nunca se levantaría contra él, una vez desaparecido el gobierno de Cromwell ${ }^{16}$.

Precisamente, Carlos II confiaba en la lealtad de un partido de realistas, compuesto tanto por protestantes como por católicos, que facilitaría enormemente su establecimiento, contando naturalmente, con las ayudas prometidas por Felipe IV. Pero para ello, continuaba siendo de vital importancia, asegurarse uno o varios puertos por los que poder acceder a su país.

Al Rey de Inglaterra le interesaba, en gran medida, que el Rey católico, a través de sus ministros en Flandes, se manifestara públicamente a favor y en apoyo suyo. Pero además, ello llevaba aparejado una serie de exigencias:

a) Libertad, tanto en los puertos de España como en los de Flandes e Italia, para todos los navíos de guerra, dispuestos a pelear por su causa.

AGS, Estado, Leg. 2090. Dicho memorial se vio en el Consejo, el 22 de abril de 1657. 
b) Felipe IV debía poner a su disposición el caudal y los efectivos suficientes para llevar a cabo el desembarco. Estas tropas, unidas a los realistas ingleses y a los adeptos existentes en Irlanda ${ }^{17}$ y Escocia harian factible la Restauración.

Por supuesto, las condiciones del ejército de Flandes y el desastroso desarrollo de la campaña del $57^{18}$ impedía ofrecer cualquier ayuda por lo que, irremediablemente, se imponía la dilación.

Para ganar tiempo, don Juan de Austria, solicitó del soberano inglés un documento firmado en donde aparecieran los nombres de las villas y puertos, dispuestos para el embarco y desembarco correspondientes, con plena garantía de su lealtad a la causa monárquica. Además, el bastardo ofreció a Carlos II, 100.000 escudos para que se fueran adelantando los preparativos pertinentes ${ }^{19}$, prometiéndole, también: 1.500 infantes veteranos que unidos a los 2.500 que tenía Carlos II alojados, constituían los 4.000 necesarios para efectuar el desembarco en las costas británicas, además de cuatro cañones y seis piezas de campaña.

De momento, no podía llevarse a cabo la empresa pero, esta dilación, se consideraba positiva por ambas partes «... que haviéndose de dilatar esta expedición por tenerlo por mas conveniente su Rey, era cierto que $\mathrm{S}$. A. le podría asistir con mayor número de gente, más municiones, viveres y dinero, y tambien se podrían asegurar más ciertamente, las negociaciones en Inglaterra y adquirir otras ${ }^{20}$.

Entretanto, se imponía el aprovechamiento de las fuerzas adeptas a Carlos II, en el propio suelo flamenco, escenario de contínuos movimientos bélicos contra franceses e ingleses ${ }^{21}$.

17 Las fuerzas irlandesas estaban formadas, en su mayor parte, por campesinos pero sus oficiales y soldados se manifestaban, mayoritariamente, a favor de la causa monárquica.

18 «Los soldados, al mismo tiempo perecen, y con razón, pues no puede llegar a más su miseria, aún después de arruinar a los paisanos que no tienen ya que les quiten" (AGS, Estado, Leg. 2090. Comunicación de don Juan desde Amberes, el 11 de mayo de 1657). A las dificultades en la llegada de hombres y dinero, se unía la falta de apoyo financiero por parte de las propias provincias flamericas debido, en gran medida, a su propia miseria labrada a través de muchas décadas de continua beligerancia.

19 AGS, Estado, Leg. 2268. En septiembre de 1657, Felipe IV comunicaba a Caracena el envío de estos 100.000 escudos para cumplir el ofrecimiento de don Juan.

20 AGS, Estado, Leg. 2090. Visto en el Consejo, el 22 de abril de 1657. También en AGS, Estado, Leg. 2268.

21 «Su Alteza procure mantener al Rey en buena fee, asegurándole el cumplimiento 
El pesimismo reinaba en Flandes al comenzar la campaña del 58 que tan nefastas consecuencias iba a tener para la Monarquía hispana con la pérdida de plazas tan importantes como Dunkerque, Bergas, Furnes, Gravelinas e Iprés. No eran demasiadas las salidas para los intereses hispanos: «... para poder defender estas provincias, la campaña que viene, es preciso antes que llegue, tomar uno de tres expedientes: o concluir la paz con Francia ${ }^{22}$, o con Inglaterra, o induçir al Señor Rey de Ungría, que con el favor de Dios no tardará mucho en ser ensalzado a la Dignidad Imperial, a que rompa la guerra a franceses y haga una viva diversión por la parte de Alemania, o que embíe aquí para la primavera, un cuerpo de exército capaz de cubrir y asegurarnos la marina y Provincia de Flandes, de la invasión de ingleses» ${ }^{23}$.

Don Juan, haciendo suyas estas premisas, no dudó en comunicarlas a la Corte. Además en el otoño de 1658 recibió diferentes avisos de que Francia, aparte de sus movimientos bélicos, desplegaba toda una campaña de acercamiento a los flamencos para desvincularlos de los intereses hispanos, en villas como Brujas y Gante. Incluso, llegó a descubrirse una conjura en la ciudad de Lieja, instigada por comisarios franceses a instancias de Mazarino y Turena ${ }^{24}$.

Sin embargo, desde Madrid se ordenaba a don Juan la realización de la expedición a !nglaterra capitulada con el Rey inglés y sólo, en caso de fracaso, se le instaba a entablar conversaciones con el gobierno de Cromwell: "Os encargo esforçeis mucho a que se execute luego dicha expediçión por las mismas consideraçiones que de ahí se me represen-

de lo prometido para la retirada y puesto que da por asentado que ya el Rey tiene junto tropas de hasta dos mil y quinientos hombres, Su Alteza procure también, sacar el provecho que pudiere dellas, en la presente campaña, pues no sería justo dejarlas en el país ociosas, saliendo el exército de V. Magestad» (AGS, Estado, Leg. 2090).

22 De hecho, Francia, había intentaoio establecer negociaciones de paz con España, pero a costa de la obtención de grandes ventajas. Así, a comienzos de julio de 1656, llegó a la Corte Monsieur Lionne, enviado por Francia para tratar acerca de la paz. En septiembre regresó nuevamente a su país sin haberse conseguido acuerdo alguno y quedando rotas las conversaciones.

Según una consulta real vista en el Consejo de Estado, «se pidieron de parte de Francia cosas tan fuera de razón y contra todos los exemplares pasados», que el Rey se negó a entrar en más negociaciones porque éstas, tal y como estaban planteadas por Francia, atentaban «a su onor y Real decoro" (AGS, Estado, Leg. 2088. Consulta del Consejo de Estado de 26 de octubre de 1656).

23 AHN, Consejos, Leg. 51436, fol. 35.

24 AGS, Estado, Leg. 2092. Carta de don Juan desde Tournay, de 27 de septiembre de 1658, informando de la conjura en Lieja. 
tan y en caso de que no suçeda, vereis si por medio de don Alonso de Cárdenas y por los conoçidos que dejó en Inglaterra o por algún otro, podría haver forma de tratar de alguna plática de composiçión con el Govierno presente ${ }^{25}$.

Pero, don Juan de Austria, no estaba dispuesto a realizar expedición alguna a Inglaterra puesto que no daba la menor credibilidad a los pactos establecidos, en su día, entre Felipe IV y Carlos II, sobre todo, por considerar de escasa importancia el apoyo que su país prestaría al monarca inglés: «... lo capitulado con aquel Rey habla en tales términos que a mi veer está oy Su Magestad libre del empeño que hiço con él» ${ }^{26}$.

Antes al contrario, se planteó muy seriamente la posibilidad de establecer una alianza amistosa con Cromwell, a modo de puente para intentar conseguir la paz con Francia aún a costa de romper, por ello, con el soberano inglés: «la pérdida que nos atrahería su desconfianza sería muy poca, pues sus troppas no pasarán hoy de quinientos hombres, los quales nos hacen más daño que provecho por los continuos robos e insolencias que cometen en el país... la caridad bien ordenada comienza de sí mismo ${ }^{27}$.

Desde luego, don Juan era consciente de que la alianza con el Protector, en caso de conseguirse, costaría un elevado precio a la Monarquía hispana, pero en cualquier caso constituía la vía más segura para firmar la páz con Francia: «más si se considera bien lo mucho que él [Cromwell] nos dará con unirse a nosotros, no me pareçe a mi que hay preçio por el qual sea cara la compra, porque peor es no tener Indias (como al presente nos sucede) que darle en ellas algún género de comerçio, lo qual, juzgo será una de sus prinçipales pretensiones» ${ }^{28}$.

Varios motivos inclinaban al bastardo a considerar la conveniencia de establecer un acuerdo con Cromwell, en detrimento de las buenas relaciones con Carlos II: la imposibilidad de defender el resto de los Reinos hispanos sin el concurso de Flandes, la irremediable pérdida de los

\footnotetext{
25 Ibidem. Despacho de Felipe IV para don Juan, de 14 de febrero de 1658.

26 Ibidem. Carta de don Juan al conde de Peñaranda desde Newport, el 30 de junio de 1658.

${ }_{27}$ Ibidem. Carta de don Juan a don Alonso de Cárdenas desde Brujas, el 14 de julio de 1658.

${ }_{28}$ Ibidem. Carta de don Juan al conde de Peñaranda desde Newport, el 30 de junio de 1658.
} 
Países Bajos a manos de franceses e ingleses, unidos, y la dilación que resultaría del establecimiento de negociaciones de paz con Francia, mientras Mazarino se mantuviera al frente de aquellos intereses ${ }^{29}$.

Desde luego, lo fundamental, como secularmente se había pensado, era el mantenimiento de Flandes en manos de la Corona católica por su importancia desde el punto de vista del concierto internacional:

- Actuaba como una especie de parachoques del imperio hispano.

- Frenaba a Francia ya que ante un eventual ataque francés a España, ésta podía invadir Francia desde los Países Bajos.

- Flandes contribuía a reducir la piratería holandesa. Concretamente, este punto de vista se vió confirmado por primera vez durante la Tregua de los Doce Años, en que, a juicio de la Corte española, el aumento prodigioso del comercio holandés en el Caribe y en las Indias Orientales, se debía directamente a la suspensión de las hostilidades en Flandes ${ }^{30}$.

A pesar de los muchos argumentos esgrimidos por don Juan, justificando el acercamiento a Cromwell, no todos los altos mandos destinados en los Países Bajos, estuvieron dispuestos a aceptarlos. Así, don Alonso de Cárdenas, ex embajador en Londres, se apresuró a calificar de muy peligroso el hecho de otorgar concesiones comerciales a los ingleses "que es lo mismo acordarles aquel comercio que poner todas las Indias a un evidente peligro de perderlas... demás de que en concediendo en ellas qualquiera género de comercio a los ingleses, le pedirían franceses en su Paz y los olandeses, si se lo negasen, romperían la Guerra para conseguirlo, siguiendo el camino por donde los ingleses lo obtuvieron y

29 «si bien en otros tiempos se ha querido disputar si Flandes era de más gasto que de provecho, en ningunos me podría yo persuadir a que con Flandes enemigo, pudiésemos subsistir en las demás partes, contra los que oy tenemos, y mucho menos aora que se halla españa tan en estremo despoblada, pobre y arruinada, sobre no poder comunicarse con las Indias y tener desmembrado un Reino como el de Portugal y lo que queda todavía en Cataluña en las manos de los enemigos de que se sigue que en la guerra de Flandes, se disputa al presente toda la monarquía” (AGS, Estado, Leg. 2092. Carta de don Juan al conde de Peñaranda desde Brujas, el 15 de julio de 1658).

30 G. PARKER, obra citada, p. 168. 
todas las demás Naciones de Europa, se valdrían de la devilidad y flaqueza de nuestras fuerzas" ${ }^{31}$.

Por otra parte, para los Reinos hispanos, a excepción de Castilla, podía resultar un agravio comparativo el ver a otras naciones manteniendo unas relaciones comerciales con las Indias, de las que ellos estaban excluidos.

Tampoco el marqués de Caracena, Gobernador de las Armas en Flandes, se mostró dispuesto a pactar con Inglaterra seguro de las grandes exigencias que ello provocaría, por parte del Lord Protector ${ }^{32}$.

Tan distintos planteamientos y vacilaciones resultaron del todo vanos, al producirse, en los comienzos de septiembre de 1658, la muerte de Oliver Cromwell lo que hacía previsible el desencadenamiento de disturbios en Londres por la formación de diferentes partidos encabezados, sobre todo, por el hijo del fallecido Protector y por el propio Carlos II.

La personalidad de aquél distaba mucho de estar a la altura de las circunstancias mientras que el nuevo Parlamento, que contaba con mayoría realista, se apresuraba a llamar a Carlos II.

La Corte madrileña aconsejó el envío de un legado desde Flandes a Inglaterra para entablar conservaciones de paz que llevaran a la elaboración de un tratado aunque sin descuidar, desde luego, el buen trato al Rey inglés, en prevención de lo que pudiera ocurrir ${ }^{33}$.

La Restauración de 1660 no volvía las cosas al estado de 1640. Dinastía y Parlamento salían, sin duda, fortalecidos. Quedaba demostrado que la institución parlamentaria era necesaria para todos los regímenes políticos, al mismo tiempo que una garantía fundamental para las libertades públicas y privadas ${ }^{34}$.

31 AGS, Estado, Leg. 2092. Carta de don Alonso de Cárdenas a don Juan de Austria desde Bruselas, el 5 de julio de 1658. En ella se mostraba más partidario de entablar negociaciones de paz con Francia.

${ }^{32} \mathrm{Ibidem}$. Carta del marqués de Caracena a don Juan desde Newport, el 13 de julio de 1658 .

33 AGS, Estado, Leg. 2092. Consulta del Consejo de 11 de octubre de 1658.

34 L. CAHEN y M. Braure, La evolución política de la Inglaterra moderna, vol. I (14851660). Méjico 1962, p. 428. Sobre la subida al trono de Carlos Il: G. Davies, The Restoration of Charles // (1658-1660). Oxford 1955; J. M. GREEN, The Reestablishment of the Church of England (1660-1663), 1977. 
Las relaciones entre Felipe IV y Carlos I/ de Inglaterra, durante el...

Carlos II, que al fin y a la postre, había ascendido al trono inglés sin necesidad de la ayuda hispana, lejos de mantener su alianza con Felipe IV, su anfitrión en los últimos años de exilio, "comprobó que sus intereses quedaban mejor atendidos mediante un acuerdo con Portugal que era una promesa de numerosos El Dorados inmensos, gracias a las recompensas y beneficios de su imperio colonial» ${ }^{35}$.

De hecho, su matrimonio con una princesa de la casa de Braganza le proporcionaría una suculenta dote y la posibilidad de combatir abiertamente al monarca hispano.

35 R. A. Strading, Europa y el declive de la estructura imperial española 1580-1720. Madrid 1983, p. 195. 